

\title{
Article Artículo Paper La mentoria social com a Q eina de treball amb joves en context d'immigració
}

\section{Òscar Prieto-Flores'}

\author{
Jordi Feu ${ }^{1}$
}

1. Universitat de Girona 
10 consideracions pràctiques a tenir en compte per a un bon funcionament de qualsevol projecte amb aquestes característiques.

Paraules clau: mentoria social, empoderament, acompanyament socioeducatiu, joves migrats

\begin{abstract}
The debate on how to empower our young people through different types of supports is increasingly relevant in a context where the number of unaccompanied minors and young people migrating alone has increased considerably. In this article the authors present social mentoring as an effective support that has been implemented in different countries. They present the origin of social mentoring and its basic characteristics, and explain how the empowerment of young people can be developed through supportive relationships that promote access to information, people and institutions that promote social inclusion. of young people and to encourage joint reflection and dialogue on how society is structured and how it can contribute to improving the present world. Finally, based on the accumulated research and management experience of the Rossinyol project promoted by the University of Girona, they highlight what they consider to be the 10 fundamental elements for mentoring to contribute to the development of young people's empowerment, and point out 910 practical considerations to take into account for the proper functioning of any project with these characteristics.
\end{abstract}

Key words: social mentoring, empowerment, socio-educational support, young migrants 
En els darrers anys hi ha hagut un augment de la preocupació per les desigualtats socials creixents en molts contextos. La política redistributiva dels Estats sembla insuficient a l'hora de donar resposta als nous reptes que tenim al davant i a la metamorfosi que la nostra societat està experimentant. També la inestabilitat política, sanitària, climàtica i social que viuen molts països, l'auge de l'extrema dreta i els populismes fan més complexa la manera d'afrontar un dels reptes més importants que tenim com a societat: que els i les joves puguin desenvolupar el seu potencial amb autonomia i amb una visió crítica del món. A més, alguns mitjans de comunicació, agències estatals o polítics dificulten aquest fet quan la imatge que divulguen de determinats joves que cerquen una millor vida en un nou context és, més aviat, demonitzadora y estigmatitzadora.

Durant els anys 80 i 90 del segle passat la mentoria orientada a joves es proposava com una solució per a millorar les condicions de vida d'aquests des d'una òptica neoliberal. Els governs de Reagan i Thatcher, i més endavant d'altres cercant una tercera via varen fer crides a la població perquè, amb les retallades de l'Estat del Benestar, la ciutadania organitzada tingués la responsabilitat d'ajudar als més pobres a sortir de la pobresa amb una certa desinhibició de la responsabilitat del rol de l'Estat en aquesta missió. Des d'aquesta perspectiva neoliberal, el prototipus de mentor sol ser representat per un home, generalment blanc i exitós en el món dels negocis. Aquesta visió paternalista -encara instaurada en alguns programes- pretén "salvar" als joves del seu context i prevenir que, finalment, acabin entrant en contacte amb xarxes de delinqüència o desviant-se pel camí "erroni". Aquest model ha estat fortament criticat en molts àmbits $i$ hi ha un debat considerable a nivell acadèmic i social si aquesta és la via per promoure la inclusió social i donar suport als joves que es troben en una situació de desavantatge social. De fet, en els darrers anys la mentoria està emergint com a forma d'acompanyament a persones refugiades a Alemanya, des d'un punt de vista intercultural i més igualitari, impulsada per organitzacions de la societat civil, algunes crítiques, amb la manca de polítiques impulsades pel govern donada la pressió i l'auge de l'extrema dreta.

El debat sobre com apoderar als nostres joves a través de diferents tipus de suports és i cada vegada serà més rellevant en un context on el nombre de menors no acompanyats i joves que migren sols o soles ha augmentat considerablement. Però què s'entén per mentoria social? Què és i com funciona? La mentoria social és l'acompanyament informal d'una persona (jove) o en situació de vulnerabilitat social per una altra persona 
voluntària que permet treballar el desenvolupament d'una sèrie d'habilitats que poden afavorir l'emancipació i apoderament dels joves i a través de la qual el voluntari/a també sol beneficiar-se'n i tenir aprenentatges. La mentoria social afavoreix la possibilitat d'accedir a xarxes de capital social. Segons Pierre Bourdieu (1980) el capital social com un "ensemble des ressources actuelles o potentielles qui sont liées à la possession d'un réseau durable de relations plus ou moins institutionnalisées d'interconnaissance et d'interreconnaissance". Bàsicament, Bourdieu utilitzava aquest concepte per a descriure com determinats grups socials mantenien alguns privilegis i com l'accés a aquest estava molt relacionat amb la classe social i les desigualtats. Nosaltres entenem que l'apoderament dels joves es pot desenvolupar a través de relacions d'acompanyament que afavoreixin l'accés a informació, persones i institucions que afavoreixin la inclusió socials dels joves i que, com destacava Freire (1997) fomentin una reflexió conjunta i de diàleg al voltant de com s'estructura la societat i com es pot contribuir a millorar el món present.

Aquest acompanyament de la díada o del grup (en el cas que la mentoria sigui grupal) és necessari que compti amb un seguiment tècnic adequat, una formació ben orientada dels voluntaris, i una sèrie de característiques que ajuden que la mentoria vagi en la direcció volguda. En aquest sentit, en els darrers anys han sortit federacions de mentoria que poden assessorar a tècnics $\mathrm{i}$ altres organitzacions sobre com afavorir processos de mentoria de qualitat. En el cas de Catalunya i Espanya, l'any 2011 va aparèixer la Coordinadora de Mentoria Social (http://www.mentoriasocial.org) i en el cas de França, recentment, s'ha creat Le Mentorat (https://www.lementorat.fr).

Al nostre parer i amb l'experiència acumulada de recerca del Gabinet de Mentoria Social de la Universitat de Girona i de la gestió del projecte Rossinyol, creiem que la mentoria social amb joves en contextos d'immigració hauria de tenir en compte els següents elements si es vol desenvolupar amb aquesta perspectiva d'apoderament assenyalada prèviament:

\section{Tenir en compte el capital social i les connexions entre mentoria formal i}

natural: Cal que els programes identifiquin, en el seu context, com les relacions de mentoria que es donen en un programa poden donar peu a altres relacions de mentoria naturals i espontànies a través de la generació de capital social i de les relacions que els joves poden establir amb agents institucionals o d'apoderament que es poden trobar al seu voltant (Stanton-Salazar, 2011). 
2. Fomentar la Mentoría Iniciada pels mateixos Joves: És necessari que tinguin en compte com el o la jove té un rol decisiu en l'elecció dels seus mentors. Algunes autores com Schwartz, Rhodes, Spencer and Grossman (2013) han destacat com persones de l'entorn del jove poden esdevenir mentors. D'aquesta forma, es donen relacions de mentoria més properes a la mentoria natural. Ara bé, cal tenir present també que no tots els joves tenen al seu abast persones que puguin esdevenir potencialment mentors i mentores. Des del nostre punt de vista, aquests mentors haurien de complir una sèrie de garanties com a) l'habilitat de saber identificar barreres sistèmiques que condicionen la vida dels joves mentorats, b) l'habilitat de transmetre en els joves la informació perquè aprenguin a navegar pel sistema i a connectar els seus interessos i motivacions amb els estudis, b) l'habilitat de ser agents d'escolta i suport emocional i c) l'habilitat d'identificar altres agents que poden donar suport als seus mentorats o mentorades.

3. Establir relacions més aviat igualitàries on el benefici és mutu: L'enfocament dels programes té en compte i fa visible com la mentoria té beneficis mutus, no només pels mentorats sinó també pels mentors. Tot i que el desenvolupament del potencial del jove es troba sempre en la centralitat de l'acció, els programes destaquen també els beneficis que aporta la relació als mentors o mentores. Aquesta consciència i orientació pot evitar que es donin relacions de mentoria marcadament etno-centristes i paternalistes que poden condicionar negativament l'emancipació dels joves.

\section{Tenir en compte una visió integral d'inclusió social dels mentorats sense par-} tir del dèficit que aquests poden tenir. En aquest sentit, Lerner (2015) destaca la necessitat que els programes que donen suport als adolescents i joves es focalitzin en desenvolupar relacions positives i sostingudes entre aquests i els adults del seu voltant perquè millorin les seves competències. A vegades, alguns programes han emfatitzat quines són les mancances dels joves a qui serveixen en comptes de centrar els esforços en crear espais i relacions que fomentin el seu desenvolupament i fent èmfasi en les seves potencialitats.

\section{Fomentar la consciència crítica sobre les desigualtats existents i el canvi social:} Sobre aquesta qüestió, han estat molts els autors i autores que des d'una lògica 
freiriana han destacat la necessitat que els mentors i mentores afavoreixin no només l'apoderament dels joves sinó també el desenvolupament d'una consciència crítica del món en el que viuen (Stanton-Salazar, 2011). En aquesta línia, Liang et al. (2013) també varen destacar la necessitat com les relacions de mentoria poden estar connectades no només amb el canvi individual sinó també amb el canvi social. És a dir, que els programes de mentoria afavoreixin una orientació de justícia social, que defineixin quin és el propòsit de les relacions de mentoria i com aquestes promouen també ciutadans actius i actives per a un món millor.

\section{Afavorir un set de dinàmiques recursives que poden utilitzar en les troba-} des que té la parella i l'assoliment dels objectius establerts: Els programes de mentoria poden oferir una sèrie de dinàmiques recursives, com apunta Rhodes (2018), que promoguin l'adquisició d'habilitats no cognitives o socio-emocionals en els joves en connexió amb els objectius d'aquests programes. Per què això sigui possible, s'han de seleccionar mentors o mentores que tinguin aquestes habilitats d'ensenyar però també s'ha d'identificar quines interaccions i pràctiques poden tenir major efecte en els mentorats o mentorades en funció dels objectius del programa. Els programes, amb aquesta informació poden orientar millor la formació dels seus mentors i fer-ne un seguiment més acurat. Per exemple, una recerca recent realitzada a Espanya amb adolescents d'origen immigrant va demostrar que determinades activitats grupals afavorien una major adquisició de les competències lingüístiques i d'habilitats socials (Universitat de Girona, 2018-2021). Evidències com aquesta, o d'altres similars, poden servir als programes de mentoria per crear aquesta cartera de recursos a través dels quals puguin formar als seus mentors de manera més precisa i s'afavoreixi una mentoria més efectiva.

\section{Promoure connexions significatives i rellevants (attunement) entre els es-} pais de relacions de mentoria (suport informal) i del sistema de benestar (suport formal): La mentoria no es substitutòria de les responsabilitats de l'Estat del Benestar. Tot i que existeixin diferents règims de l'Estat del Benestar segons el context (Esping-Andersen, 1990), el suport informal que ofereixen els mentors i mentores hauria de ser complementari a les polítiques públiques i el 
suport formal i dels professionals del món educatiu i social. En aquest sentit, és necessari observar com els programes de mentoria poden col-laborar amb els professionals d'aquests àmbits per a poder complementar-se mútuament.

\section{Tenir més en compte la qualitat de les relacions de mentoria que no pas la} quantitat: Alguns programes destaquen la necessitat de promoure quantes més relacions de mentoria millor. Aquesta dinàmica es sol fer palesa en les memòries anuals de les entitats quan evidencien, de forma explícita, el nombre creixent de les relacions de mentoria que han realitzat en els darrers anys. A vegades, el motiu que impulsa a les organitzacions a aquesta dinàmica de creixement o expansió ve condicionada pels òrgans finançadors i sol estar lligada a la percepció errònia que les relacions de mentoria, per si soles, ja generen una millora social i de benestar en els joves, i que quantes més, millor.

\section{Tenir presents les relacions amb la família del jove i de la seva comunitat (en} el cas que sigui possible): Sovint, es parteix de la visió que les trobades han de ser fora del barri o de l'entorn del jove perquè "el barri o l'entorn on viu es troba estigmatitzat". Si bé, a vegades és important sortir del barri per acompanyar-los a veure recursos i institucions a les quals no solen tenir accés (e.g. museus, campus universitari, descobrir la ciutat, etc.); també és central que els mentors i mentores es trobin còmodes en el context habitual on el o la jove ha està construint el seu món de la vida quotidiana, interactuant i establint relacions de confiança amb els seus pares, familiars i comunitat.

\section{Definir els objectius del programa conjuntament amb els col-lectius a qui} es serveix: Sovint, els objectius dels programes són definits per l'organització que els porta a terme o els seus finançadors (ja sigui agència de govern o entitat filantròpica). Generalment, intenten donar resposta a una problemàtica social, construïda socialment, i perceben la mentoria com una eina útil i de suport per a les persones que viuen aquesta situació de desavantatge. Tot i així, si els programes i finançadors volen promoure objectius i enfocaments més inclusius, caldria tenir en compte la veu dels joves participants i les seves famílies (si és possible) per analitzar si les seves preocupacions són les mateixes, i si l'enfocament i els objectius sorgeixen d'un diàleg entre els diferents agents que hi participen. 


\section{El cas del projecte Rossinyol i la seva escalabilitat a comarques de Girona. Alguns} elements d'èxit a tenir en compte per a l'escalabilitat de programes de mentoria social

El projecte Rossinyol va néixer l'any 2005 a la Universitat de Girona fruit d'un projecte europeu Comenius liderat per la Universitat de Malmö. Lobjectiu d'aquest projecte era replicar un programa de mentoria que es va iniciar el 1997 a Suècia on estudiants universitaris feien de mentors o mentores d'infants de famílies nouvingudes a diferents universitats europees. En el cas de la Universitat de Girona es va optar per adaptar el model de Malmö: la mentoria si bé se centra en infants i joves nouvinguts s'ha ampliat a infants i joves «autòctons» que provenen d'entorns econòmics i socials vulnerables; i, per altra banda, aquests infants $i$ joves no provenen d'un sol municipi sinó que ho fan de 13 ciutats i pobles diferents, en el nostre cas de comarques gironines.

Després de quinze anys d'experiència hem pogut constatar, amb humilitat, que hi ha alguns elements d'escalabilitat i d'implementació que poden ser útils de cara a nous programes o projectes que es vulguin implementar amb joves en contextos d'immigració. Aquests són els següents:

1. Definició clara dels objectius i plausibilitat dels mateixos: el projecte Rossinyol sovint diem que es tracta d'un projecte d'èxit perquè s'edifica sobre uns objectius concrets i al nostre entendre clars: i) afavorir la inclusió social, cultural, lingüística i espacial; i ii) fomentar actituds positives entorn de l'educació formal que comportin un progrés dels infants i els joves en el sistema educatiu. Aquests objectius es porten a terme mitjançant la creació d'un vincle afectiu i positiu entre el mentor i el mentorat, i mitjançant la realització d'activitat lúdiques i culturals que afavoreixin un procés d'ensenyament i aprenentatge en un context donat per descomptat.

2. Selecció i formació dels mentors (voluntariat): si bé son molts els nois i noies aspirants a ser mentors bé és veritat que no tots son aptes per ser-ne. Cal, abans de res, demostrar interès i compromís pel projecte, tenir temps per dedicar-s'hi i tenir tot un seguit d'habilitats i destreses mínimes que s'aniran eixamplant a mesura que es desplegui el projecte. Per assegurar l'èxit del projecte es porta a terme un procés de selecció que consta, bàsicament, de les fases següents: els aspirants a 
mentors es postulen per ser-ne, omplen una enquesta elaborada per l'equip impulsor, s'analitzen els resultats i en els casos que generen dubtes, se'ls fa una entrevista personalitzada. Els mentors i mentores seleccionats reben una formació específica que consta de quatre sessions en les que es treballen a fons: i) la metodologia del projecte, ii) aspectes relacionats amb la diversitat cultural i la integració, iii) en una de les sessions venen exmentors a explicar la seva experiència (una d'èxit i una de problemàtica) i a la darrera sessió, iv) els enllaços territorials (les persones que estan en contacte amb els centres i son coneixedors dels mentorats i les seves famílies) coneixen personalment els mentors per, així, fer un aparellament el màxim d'ajustat amb els mentorats.

3. Acompanyament permanent dels mentors. Des del nostre punt de vista tots els programes de voluntariat en general, i els de mentoria en particular requereixen un acompanyament permanent i sostingut dels mentors per part d'un professional que formi part del nucli dur del projecte. En el cas del Rossinyol, l'acompanyament es fa efectiu a partir de qui fa les funcions de suport tècnic (persona integrada a l'equip de la Universitat de Girona) així com dels enllaços territorials de cadascun dels municipis participants.

\section{Pla senzill, eficaç i eficient per detectar els problemes que puguin sorgir en el}

transcurs del projecte. A la formació inicial s'explica el més clarament possible que és «normal» que apareguin problemes durant la mentoria (mentorats que no assisteixen a les trobades, famílies que presenten resistències latents perquè els seus fills quedin amb les mentors, construcció de vincles febles entre mentors i mentorats, mentors que en època d'exàmens disminueixen la periodicitat de les trobades, etc.). La nostra experiència ens diu que si els problemes es detecten a temps, fâcilment se'ls pot donar la volta i reconduir-los. L'equip tècnic del Rossinyol i els enllaços territorials ens ocupem d'aquesta tasca. Un cop hem detectat el problema: i) el definim i el caracteritzem, ii) proposem diverses solucions (sempre i quan el problema ho permeti), iii) escollim la més apropiada en cada cas, iv) l'executem i finalment, v), l'avaluem. Fent-ho així, la majoria de problemes es resolen satisfactòriament assolint un 95\% d'èxit en el programa.

\section{Repartiment clar de responsabilitats entre els agents que en formen part del} projecte. Sovint afirmem que el projecte Rossinyol és un projecte senzill, de sen- 
tit comú, altament eficaç i eficient. Amb tot, perquè el projecte funcioni cal que tots els agents que hi participen s'ocupin de la responsabilitat que els hi pertoca. A grans trets, l'equip Rossinyol de la Universitat de Girona (format pel director, coordinador i suport tècnic) ens ocupem, essencialment, de la direcció política del projecte i d'allò que concerneix essencialment als mentors. La nostra tasca se centra sobretot en: definir i revisar periòdicament els objectius del projecte; concretar la metodologia i l'organització per portar-lo a terme; difondre el projecte a la universitat; establir el procés de selecció dels mentors; formar els mentors; establir les relacions amb els ajuntaments i enllaços territorials; concretar el perfil dels mentorats; i portar a terme el seguiment dels mentors i de la mentoria en el seu conjunt. Els enllaços territorials, bons coneixedors del territori (municipi o barri on es porta a terme el Rossinyol) s'ocupen d'allò que atén als mentorats i les seves famílies, aspecte que en bona mesura és compartit amb els tutors i tutores dels centres educatius. La festa inicial (que dona pas a l'obertura anual de la mentoria) i la festa final (de comiat) l'organitzen essencialment els enllaços territorials amb la col-laboració, en alguns casos, dels mentors i dels centres educatius dels mentorats.

6. Acomodació del projecte a la realitat de cada municipi. Partint d'una concepte de política descentralitzada i de la confiança plena amb tots els agents que d'una manera o altra participen en el projecte, el projecte Rossinyol procura adaptar-se a la realitat de l'entorn per tal que les necessitats que té aquest, es puguin incloure. Fent-ho d'aquesta manera, el projecte Rossinyol de la Universitat de Girona té un denominador comú a tot arreu on es desenvolupa per bé que cada municipi te la llibertat d'adaptar una part dels objectius (emfatitzant, per exemple, uns objectius per damunt dels altres) i, sobretot, d'acomodar l'estructura organitzativa així com el funcionament. El resultat d'aquest plantejament és, entre d'altres, que cada territori se sent «seu» el projecte.

7. Creixement lent, sostingut i controlat del projecte: El primer any del projecte Rossinyol es va iniciar amb quatre mentors i quatre mentorats del mateix centre educatiu i de la mateixa ciutat. Avui dia el Rossinyol-UdG som 130 mentors, 130 mentorats de 23 centres educatius de primària i 15 de secundària de 12 municipis de comarques gironines. El projecte Rossinyol de la $\mathrm{UdG}$, a més, ha ajudat a 
estendre el projecte a Barcelona, Tarragona, Pamplona, Donosti, Bilbao, i Granada. El creixement i difusió tant en l'àmbit nacional com estatal del projecte considerem que ha estat possible, entre altres factors, gràcies a que s'ha desplegat de manera lenta, progressiva i segura, és a dir: a mesura que anàvem consolidant passos, protocols i metodologies tastades ens plantejàvem incrementar molt mesuradament el nombre de mentors. Aquest principi l'hem recomanant sempre en els municipis que ens demanen iniciar el projecte de mentoria.

8. Rendiment de comptes: El projecte Rossinyol és un dels projectes de responsabilitat social més importants de la Universitat de Girona finançat amb fons públic. En conseqüència, és de justícia que al final de cada exercici es doni compte com, quan i en què s'han gastat els diners mitjançant una memòria pública. Aquesta memòria recull també una anàlisi de com ha anat el projecte incidint, sobretot, en aspectes organitzatius i de funcionament.

9. Incorporació d'elements tecnològics de seguiment de les parelles: Finalment, destacar que amb la possibilitat d'innovar que hem tingut gràcies a la investigació Recercaixa Applying Mentoring incorporàrem l'ús, per part de les nostres mentores i mentors, de l'aplicació mòbil Messagenes. Aquesta aplicació ens permet fer un seguiment en temps real de com estan anant les trobades que realitzen les parelles, si tenen alguna dificultat, i avançar-nos a possibles futurs problemes o incidències que aquestes puguin tenir.

\section{Referències bibliogràfiques}

Bourdieu, P. (1980). "Le Capital Social. Notes Provisoires". Actes de la Recherche en Sciences Sociales. 31, 2-3.

Esping-Andersen, G. (1990). The Three Worlds of Welfare Capitalism. Cambridge: Harvard University Press.

Freire, P. (1997). Mentoring the Mentor. A Critical Dialogue with Paulo Freire. New York: Peter Lang. 
Lerner, R. M. (2015). "Promoting positive human development and social justice: Integrating theory, research and application in contemporary developmental science”. International Journal of Psychology, 50(3), 165-173.

Liang, B., Spencer, R., West, J., and Rappaport, N. (2013). "Expanding the reach of youth mentoring: Partnering with youth for personal growth and social change". Journal of Adolescence, 36, 257-267.

Universitat de Girona (2018-2021). Applying Mentoring: Innovacions socials i tecnològiques per a la inclusió social de la població immigrant i refugiada. Projecte finançat en el programa RECERCAIXA 2017, per l'Obra Social de "la Caixa” i l'Associació Catalana d’Universitats Públiques.

Rhodes, J.E. (2018). Research on quality of mentoring relationships: how to build strong relationships. [Video available on: https://mentoringsummit.eu/speakers/jean-rhodes]

Schwartz, S.E., Rhodes, J.E., Spencer, R. and Grossman, J.B. (2013). "Youth Initiated Mentoring: Investigating a New Approach to Working with Vulnerable Adolescents". American Journal of Community Psychology, 52 (1-2), 155-169.

Stanton-Salazar, R.D. (2011). "A Social Capital Framework for the Study of Institutional Agents and Their Role in the Empowerment of Low-Status Students and Youth”. Youth E Society, 43(3), 1066-1109. 
Xedagogia i Treball Social

Revista de Ciències Socials Aplicades

Edita: Universitat de Girona

Disseny i maquetació: info@clam.cat · 647427732

Dipòsit Legal: GI.904-2010

ISSN: 2013-9063 